\title{
Factors Determining Quality of Life of Elderly People in Rural Nepal
}

\section{Joshi MR*}

\author{
Department of Population Studies, Kailali Multiple Campus, Tribhuvan University, Nepal
}

\begin{abstract}
Introduction: Quality of Life (QOL) of elderly people is an important issue with respect to the increasing proportion of elderly population in Nepal.

Objective: The study aimed to examine the factors determining QOL of Nepali elderly in rural Nepal.

Methods: This is a cross-sectional study carried out in 2017 in Kailali district, far west province of Nepal. Total sample size for this study was 547. World Health Organization Quality of Life-Bref (WHOQOL-Bref) instruments were used to assess elderly people's quality of life.

Results: This study exhibited that physical health problem of elderly people play vital role in determining their QOL. There is strong negative relationship $(-0.505)$ between physical health problem and overall QOL index of elderly people which indicates reducing physical health problem of elderly leading to significant improvement in their QOL. Physical health problem independently contribute 24.6 percent towards overall QOL as well as contribution with other variables like stress in life and involvement in social activities contribute 36.7 percent.

Conclusion: It implies policy implication of giving equal attention in strengthening our health and health care system to care physical and psychological health care needs of elderly people.

Keywords: Ageing; Elderly abuse; Living arrangements; Involvement in social activities; Quality of life (QOL); Stress in life
\end{abstract}

\section{INTRODUCTION}

Ageing of population is one of the major achievements and most significant characteristics of the twenty first century which reflects the success of the process of human development. Singh argued that continuous increase in old people and a decline in the population of young people all over the world are creating demographic imbalances and humanitarian, social and economic problems in many countries especially developed countries. For the last two decades, social scientists and demographers all over the world, including Nepal, are trying to explore the dynamics of ageing [1]. The first World Assembly on Ageing held at Vienna in 1982, United Nations International Conferences on Ageing and Urbanization in 1991 and Senior Citizen Act of Nepal 2006, defines elderly persons as those who are 60-years and above [2,3]. This study follows the same definition. It is because the definition of United Nations is considered as internationally recommended definition. In addition, the definition of senior citizen act and regulation of Nepal is considered as nationally recommended definition in the case of Nepal.

Quality of Life (QOL) is a multi-dimensional concept. The World
Health Organization's Quality of Life Group (WHOQOL-Group, 1998) has defined QOL as: An individual's perception of their position in life, in the context of the culture and value systems in which they live and in relation to their goals, expectations, standards and concerns. It is a broad ranging concept affected in a complex way by the person's physical health, psychological state, personal beliefs, social relationships and their relationship to salient features of their environment [4].

Quality of life is one of the central concepts in ageing research. Two different traditions can be distinguished in this respect: Concepts which define QOL in terms of objective living conditions and concepts which define QOL in terms of subjective evaluation [5]. Objective quality of life can be measured by the extent to which a person has access to and command over relevant resources. Subjective QOL, in contrast, emphasizes an individual's perceptions and evaluations. Subjective QOL depends on the individual person and lies in the "eye of the beholder" [6]. The distinction between objective and subjective QOL implies that the two concepts are not congruent and, hence, not redundant. The subjectively perceived QOL may be low even when observers agree that the objective living situation may be characterized as very good

Correspondence to: Joshi MR, Associate Professor, Department of Population Studies, Kailali Multiple Campus, Tribhuvan University, Nepal Nepal, Tel: +977 91-521223; E-mail: drmahendrarajjoshi@gmail.com

Received: April 21, 2020, Accepted: May 22, 2020, Published: May 29, 2020

Citation: Joshi MR (2020) Factors Determining Quality of Life of Elderly People in Rural Nepal. J Gerontol Geriatr Res 9: 510. doi: 10.35248/21677182.20.9.510.

Copyright: (C) 2020 Joshi MR. This is an open-access article distributed under the terms of the Creative Commons Attribution License, which permits unrestricted use, distribution, and reproduction in any medium, provided the original author and source are credited. 
and vice versa, not all people in modest or poor living situations may be dissatisfied with their lives [7].

Enhancing or maintaining the QOL of the elderly persons is a social and moral obligation of governments and society as a whole. Fulfilling these responsibilities depend on the extent to which countries have prepared both economically and socially to care for this segment of the population. In this context, Subedi [8] argued that the growth of elderly population in Nepal has taken place in a situation where neither the household nor the nation is in a position to genuinely support them for their comfortable living. Providing care for the aged has never been a problem in Nepal where a value based joint family system is dominant. However, the coping capacities of the younger and the older family members are now being challenged under various circumstances resulting in neglect of elderly people in many ways. In this context, the present study tries to examine the factors which contribute the QOL in old age. In Nepal, there are very little studies carried out concerning the QOL. Past study has focused on loneliness depression functional disability, self-reported health, sleep quality, elderly abuse, perceived quality of life, living arrangement and quality of life, physical and mental health status [9-16]. It is unclear that what are the factors that determine the QOL of elderly people? This study has tried to fill up this gap.

The main objective of this study was to assess the differential of QOL of Nepali elderly in rural Nepal. Specifically, the differential of QO according to demographic variables (such as: age, sex, marital status and household size) and socio-economic variables (such as: living arrangements, education, involvement in decision making, involvement in social activities, physical health problem, stress in life, abuse, caste/ethnic group, medical health check-up, having pension/social security allowance, and land/property ownership) were assessed.

\section{MATERIALS AND METHODS}

This is a cross sectional study carried out in 2017. All the elderly people $\left(\right.$ aged $\left.-60^{+}\right)$of the rural area of Kailali district constituted the population of the study. Elderly people (aged 60-years and above) of the selected households were respondents of the study. In the survey a total of 396 households of the area were visited and 547 elderly (Male=225 and female=322) aged 60-years and above were interviewed individually. This sample size accounted for 28.8 percent of the total households with at least one elderly person (aged $60^{+}$) in the study area. The Sample size for the study has been calculated by using Yamane formula with 95\% confidence level [17]. Multi-stage sampling design was adopted for this study. For getting quantitative information, structured interview was employed and qualitative information was collected. Among the various types of research designs, descriptive and explanatory research designs were adopted for this study. WHOQOL-BRIF instruments were used to elicit elderly people's quality of life. The data was statistically analyzed by using SPSS version 20.0. For the statistical analysis, frequency table, percentage, mean, standard deviation and multiple regression analysis were performed.

The items related to QOL was then scored (based on WHOQOL syntax) to calculate for the mean values of four domains (physical health, psychological state, social relations and environment). The mean scores of four domains of QOL of elderly people were calculated. High mean values signified better QOL. Finally, an overall QOL Index was designed exclusively for this study by taking the means of all four domains of QOL i.e. physical health, psychological state, social relations, and environment. The potential score of the index ranges between 4-20 scales. It is interpreted that 4 indicates the 'worst' and 20 indicates the 'best' level of quality of life of elderly people.

Stepwise multiple regression analysis was used to identify the combinations of variables that best predicts the overall QOL of elderly people. 'Overall QOL index' was the dependent variable in this study while selected fifteen factors were considered as the independent variables in this analysis. In this technique, all the candidate variables in the model are checked to see if there significance has been reduced below the specific tolerance level. If a non-significant variable is found, it is removed from the model. A p-value of less than 0.05 was required for statistical significance. Variables whose p-value was more than 0.05 was removed. Coefficient of Determination $\left(\mathrm{R}^{2}\right)$ represents the explanatory power of independent variables in explaining the dependent variable. The selected variables for regression analysis were: age, sex difference, marital status, household size, living arrangement, abuse, involvement in decision making in the family, involvement in social activities, stress in life, physical health problem, caste/ethnic group, medical health care (routine health check-up),education, land/property ownership and having old age security allowance.

\section{RESULTS}

\section{Background characteristics of respondents}

Demographic and socio-economic characteristics of older people play an important role in understanding their quality of life and well-being. Demographic characteristics such as age, sex, marital status, household size and socio-economic characteristics like caste/ethnicity, educational status, living arrangement, elderly abuse, stress in life, involvement in decision making in the family, involvement in social activities, physical health problem, land/ property ownership, medical health check-up, receiving status of old age security allowance. A detail about these socio-economic and demographic characteristics help in providing a basis and better understanding about quality of life of older people (Table 1).

The table given shows that the mean age of research participants was 71.43-years $(\mathrm{SD}=8.006)$. Majority of the respondents were female (58.9\%). Over three fifth (63.1\%) respondents were married. Average household size was 6.87 (SD \pm 3.297$)$. Overwhelming majority of respondents $(85.2 \%)$ of respondents reported that they were residing with their son/daughter in law followed by spouse only (7.9\%). It was found that about less than two percent $(1.5 \%)$ respondents were residing with their daughter/ son in law. Furthermore, it was also found that about three percent (2.7\%) respondents were residing alone. In this study, Onefofth of respondents $(20.4 \%)$ reported that they have severe stress in life. One in every seven $(14.8 \%)$ of the respondents reported to have faced some form of abuse. Most of the literate elderly (18.7\%) were found that they had no formal education followed by Basic education (4.0\%), secondary level education and SLC and above $(1.1 \%)$ in the study area. It was observed that over two third of the respondents $(68.9 \%)$ have at least one physical health problem. About half of the respondents (48.4\%) had owned some land in 
Table 1: Percent distribution of respondents according to background variables.

\begin{tabular}{|c|c|c|c|}
\hline Background characteristics & Number & Percent & Indices \\
\hline \multicolumn{4}{|c|}{ Demographic Factors } \\
\hline \multicolumn{4}{|c|}{ Age (Years) } \\
\hline $60-64$ & 112 & 20.5 & \multirow{6}{*}{ Mean age $=71.43 \mathrm{SD} \pm 8.006$} \\
\hline $65-69$ & 132 & 24.1 & \\
\hline $70-74$ & 138 & 25.2 & \\
\hline $75-79$ & 76 & 13.9 & \\
\hline $80-84$ & 47 & 8.6 & \\
\hline $85^{+}$ & 42 & 7.7 & \\
\hline \multicolumn{4}{|c|}{ Sex } \\
\hline Male & 225 & 41.1 & \multirow{2}{*}{ Sex ratio $=69.88$} \\
\hline Female & 322 & 58.9 & \\
\hline \multicolumn{4}{|c|}{ Marital Status } \\
\hline married & 345 & 63.1 & \\
\hline Others* & 202 & 36.9 & \\
\hline \multicolumn{4}{|c|}{ Household Size } \\
\hline Five persons and more & 440 & 80.4 & \multirow{2}{*}{ Mean $=6.87, \mathrm{SD} \pm 3.297$} \\
\hline Upto four persons & 107 & 19.6 & \\
\hline \multicolumn{4}{|c|}{ Socio-Economic Factors } \\
\hline \multicolumn{4}{|c|}{ Caste/ethnic group } \\
\hline Tharu & 409 & 74.8 & \\
\hline Non-Tharu & 138 & 25.2 & \\
\hline \multicolumn{4}{|c|}{ Involvement in social activities } \\
\hline Frequently & 9 & 1.6 & \\
\hline Occasionally & 232 & 42.5 & \\
\hline Never & 306 & 55.9 & \\
\hline \multicolumn{4}{|c|}{ Involvement in decision making in the family } \\
\hline Improved & 13 & 2.4 & \\
\hline Remain the same & 248 & 45.3 & \\
\hline Declined & 286 & 52.3 & \\
\hline \multicolumn{4}{|c|}{ Elderly abuse } \\
\hline Yes & 81 & 14.8 & \\
\hline No & 466 & 85.2 & \\
\hline \multicolumn{4}{|c|}{ Stress in Life } \\
\hline Hardly ever & 164 & 23.6 & \\
\hline Moderate & 271 & 56.0 & \\
\hline Severe Stress & 112 & 20.4 & \\
\hline \multicolumn{4}{|c|}{ Living arrangement } \\
\hline Living with spouse & 43 & 7.9 & \\
\hline Living with son/daughter in law & 466 & 85.2 & \\
\hline Living with Daughter/son in law & 8 & 1.5 & \\
\hline Grand children & 12 & 2.2 & \\
\hline Other family members & 3 & 5.0 & \\
\hline Alone & 15 & 2.7 & \\
\hline \multicolumn{4}{|c|}{ Level of education } \\
\hline Illiterate & 415 & 75.9 & \\
\hline Literate but not formal education & 102 & 18.6 & \\
\hline Basic education (1-8) & 22 & 4.0 & \\
\hline Secondary education (9-12) & 6 & 1.1 & \\
\hline Higher education (bachelor ${ }^{+}$) & 2 & 0.4 & \\
\hline
\end{tabular}

Physical health problem

Yes

377 


\begin{tabular}{ccc}
\hline No & 170 & 31.1 \\
\hline & Medical Check-up & 57.4 \\
\hline Yes & 314 & 42.6 \\
\hline No & 233 & \\
\hline & Land / property ownership & 48.2 \\
\hline Yes & 265 & 51.6 \\
\hline No & 284 & \\
\hline & Having Pension/Old age security allowance & \\
\hline Yes & 366 & 36.9 \\
\hline No & 181 & 100.00 \\
\hline N & 547 &
\end{tabular}

Note: ${ }^{*}$ others include ever married, divorced, separated, widow/widower

the study area. Most of the respondents $(74.8 \%)$ belong to Tharu (indigenous group) community. Majority (66.9\%) of respondents were found to be receiving the old age allowance. Over half of (57.4\%) the respondents have medical check-up during the last one-year. Over half (52.3\%) respondents reported that the decision making role in the family has been declined as they grew old. Over half $(55.9 \%)$ of the respondents reported that they have never attended any public meeting during the last 12 months.

\section{Major factors that determine QOL of elderly people}

The extent of influence of each of the independent variable varies according to elderly people. These independent factors, besides having individual influence on QOL of elderly people have influence on their QOL in association with other variables. Hence, to elicit these combinations and relative contribution of these variables in determining QOL of elderly people, fifteen selected variables named above entered stepwise in multiple regressions (Table 2). Overall QOL index was the dependent variable of this study while the selected fifteen factors were considered as the independent variables of this analysis. Variables relating to significant regress or are considered as determining factors and variables relating to insignificant regress or were removed from the process. Among the 15 variables, 10 variables were accepted and remaining 5 variables were removed from the process. Among the independent variables, 10 variables out of 15 significantly influenced their overall QOL index. The significant predictors of overall QOL index were: physical health problem, stress in life, involvement in social activities, age group, caste/ethnic group, abuse, living arrangements, involvement in decision making in the family, household size and land/property ownership. This model explained 46 percent of variance $\left(R^{2}=46.1 \%\right.$; Adj. $\left.R^{2}=45.1 \%\right)$ in QOL of elderly. These factors differed in the level of their contribution. Their contribution in combination with other factors also showed different influences on overall QOL of elderly people. A discussion on the role of these significant variables that have been identified based on their contribution to overall QOL is presented as below.

\section{Physical health status and overall QOL index}

Elderly people's physical health status has emerged as the most powerful contributor to their overall QOL that independently as well in combination with other factors (like: stress in life, involvement in social/community activities, age group, caste/ethnic group, abuse, living arrangements, involvement in decision making, household size, land/property ownership) influenced overall QOL of elderly people. Physical health problem independently contributed about 24.6 percent variation towards the overall QOL of elderly people. It is statistically significant. Hence, physical health problem of elderly people plays a vital role in determining overall QOL of elderly people. Elderly people with severe physical health problem have negative impact on overall QOL. Improving their physical health problem will greatly improve the QOL of elderly people. These findings reiterate the importance of improving health outcomes in later life that has a direct impact on an individual's well-being.

\section{Stress in life and overall QOL index}

Elderly people's perception about the level of stress in their lives has also emerged as a second important factor in influencing their overall QOL. It was observed that stress in life independently as well as in combination with other factors (like: involvement in social activities, age group, caste/ethnic group, abuse, living arrangements, involvement in decision making, household size, land/property ownership) influenced overall QOL of elderly people. Elderly people who hardly experience any stress had better overall QOL compared to those who have perceived very severe stress in normal life. Stress in life in addition to physical health status significantly improves the QOL of elderly people as observed in the total sample where its independent contribution was significant. Stress in life independently contributed $8.2 \%$ variation towards overall QOL index of elderly people in the study area.

\section{Involvement in social/community activities and overall QOL index}

Factors that promote elderly people's social mobility especially their frequency of participation in public meeting, religious programmed and community activities have a significant impact on their overall QOL. It was observed that frequency of participation on social and religious activities independently as well as in combination with other factors (like: age group, caste/ethnic group, abuse, living arrangements, involvement in decision making, household size, land/property ownership) influenced elderly people's overall QOL. This factor was observed to contribute significantly towards improving QOL of all elderly people and was the third highest contributor to overall QOL of elderly people. Involvement in social activities independently contributed $4.0 \%$ variation towards overall QOL index of elderly people. Community participation improves social contact and awareness by promoting their psychological and physical well-being besides improving their 
Table 2: Stepwise regression model showing variance in overall QOL index of elderly people.

\begin{tabular}{|c|c|c|c|}
\hline Model & Variables in model & $\mathrm{R}^{2}(\%)$ & $\mathrm{R}^{2}$ change (\%) \\
\hline 1 & PHP & 24.6 & $24.6^{* *}$ \\
\hline 2 & PHP, SIL & 32.8 & $8.2^{* *}$ \\
\hline 3 & PHP, SIL, ISA & 36.8 & $4.0^{* *}$ \\
\hline 4 & PHP, SIL, ISA, AG & 40.2 & $3.4^{* *}$ \\
\hline 5 & PHP, SIL, ISA, AG, CEG & 41.9 & $1.7^{* *}$ \\
\hline 6 & PHP, SIL, ISA, AG, CEG, AB & 43.2 & $1.3^{* *}$ \\
\hline 7 & PHP, SIL, ISA, AG, CEG, AB, LA & 44.4 & $1.2^{* *}$ \\
\hline 8 & PHP, SIL, ISA, AG, CEG, AB, LA, IDMF & 45.1 & $0.7^{* *}$ \\
\hline 9 & PHP, SIL, ISA, AG, CEG, AB, LA, IDMF, HHS & 45.7 & $0.6^{*}$ \\
\hline 10 & PHP, SIL, ISA, AG, CEG, AB, LA, IDMF, HHS, LO & 46.1 & $0.4^{*}$ \\
\hline
\end{tabular}

Overall Model, $\mathrm{R}^{2}=46.1 \%$; Adj. $\mathrm{R}^{2}=45.1 \%$

Notes:

- "indicates $\mathrm{p}<0.05,{ }^{* *}$ indicates $\mathrm{p}<0.01$

- PHP: Physical health Status; SIL: Stress in life; ISA: Involvement in social activities; AG: Age group; CEG: Caste/ethnic group; AB: Abuse; LA: Living arrangements; IDMF: Involvement in decision making in the family; HHS: Households size; LO: Land/property ownership.

contact with environmental factors. This suggests the need to improve the frequency of participation of elderly people to their community which provides them opportunities to interact more with their physical as well as social environment that consequently improved their overall QOL.

\section{Age and overall QOL index}

Age is an important indicator that considerably explains the QOL of elderly people. It is appeared as an important determinant of their overall QOL. Elderly people with lower age had better overall QOL as compared to higher age. It was observed that age independently contributed to about 3.4\%towards overall QOL. Besides its individual influence, age in combination with other factors (like: caste/ethnic group, abuse, living arrangements, involvement in decision making in the family, household size and land/property ownership) influences overall QOL of elderly people.

\section{Caste/ethnic group and overall QOL index}

It was observed that caste/ethnicity of elderly people independently as well as in combination with other factors influenced overall QOL. This factor was observed to the fifth highest contributor to overall QOL of elderly people. Caste/ethnicity independently contributes to $1.7 \%$ towards overall QOL. Besides its individual influence, caste/ethnicity in combination of other factors (like: abuse, living arrangements, involvement in decision making in the family, household size and land/property ownership) influence overall QOL of elderly people.

\section{Elderly abuse and overall QOL index}

Elderly people facing abuse (neglect, violence) have significantly lower overall QOL as compared to those never experiencing abuse. Abuse has emerged as a significant factor determining the overall QOL of elderly people. It was observed that abuse independently contribute to $1.3 \%$ towards overall QOL as well as in combination with other factors (like: living arrangements, involvement in decision making, household size and land/property ownership) influence overall QOL of elderly people. It is further noticed that family members are the prime perpetrators. It points towards the need to strengthen the intergenerational bonds. Programmatic interventions need to be developed with a focus on 'family relations' i.e. care and provide affection for elderly persons in the family. This will have multiple benefits like improving self-esteem, autonomy and health of elderly people that will enhance their overall QOL.

\section{Living arrangements and overall QOL index}

Living arrangements is an important indicator that considerably explains the QOL of elderly people. It is appeared as an important determinant of their overall QOL. Elderly people living with son/ daughter in law had better overall QOL as compared to those who were living alone and other family members. It was observed that living arrangements independently contributed to about $1.2 \%$ towards overall QOL. Besides its individual influence, living arrangements in combination with other factors (like: involvement in decision making in the family, household size and land/ ownership) influences overall QOL of elderly people.

\section{Other factors and overall QOL index}

Other factors such as involvement in decision making in the family, household size and land/property ownership also found significantly influence QOL of elderly people. However, these factors independently contribute less than one percent each towards variance in overall QOL. The combined effect of all these three factors was found about $1.7 \%$ towards variance in overall QOL of elderly people. Elderly people whose involvement in decision-making in the household has improved since they have grown old, has a positive influence on their overall QOL. Hence, QOL of elderly people can be enhanced by designing interventions towards educating the family members on giving opportunities to elderly people to contribute towards decisions making on household issues. In addition, awareness and education of elderly people to continue participating in household decision making as they grow older and utilize their rich experience will help in harmony in the household as well as improve their overall QOL. Besides, household size and land/property ownership enhanced elderly people financial security which has significant impact on overall QOL of elderly people. This model suggests that elderly people having with no physical health problem, lower level of stress 
in life, frequently/actively involved in social activities, having lower age, elderly people belongs to Non-Tharu ethnic group, never experienced abuse, living with son/daughter-in-law, perceiving active role play in the decision making in the family, have a family size with 3-4 members and having ownership on land/property had significantly higher overall QOL index.

\section{DISCUSSION}

Stepwise multiple regression analysis was performed to test the variables to examine the factors determining the QOL of elderly people. Fifteen regressors were tested by applying stepwise multiple regression analysis. It was found that 10 out of 15 regressors were observed statistically significant. Independent variables relating to significant hypothesis were considered factors determine overall QOL of elderly people. So, this study identified 10 factors like: physical health problem, stress in life, involvement in social activities, age, caste/ethnic group, abuse, living arrangements, involvement in decision making in the family, household size and land/property ownership as a prime factors that determine the QOL of elderly people. Literature on previous studies also identified the factors that determine the QOL of elderly. In this context, Gabriel and Bowling argued that having enough money is one of the key determinants of QOL of elderly people [18]. Maheswori had identified the economic status has significant impact on QOL of elderly people [19]. Gupta revealed that seven variables (like: satisfaction with general health, years of education, change indecision making, abuse, frequency of meeting with family members and friends, stress in life and age of the respondents) significantly influenced their overall QOL index [20]. Scholars have identified the education as the determinant of QOL of elderly people [20-22]. Scholars have identified the involvement in social activities and decision making process as one of the determinant of QOL in old age [21-25]. They argued that participation in social activities has significance influence on QOL of elderly.

\section{LIMITATIONS OF THE STUDY}

The limitations of the study are as: This study is limited on the selected households of rural area of Kailali district and focused only on the elderly people aged 60 years and above. This study has adopted simple as well as advance statistical tools such as frequency, percentage, mean, standard deviation, correlation analysis and multiple regression analysis. The study has used the responses of elderly themselves to examine the factors determine quality of life of elderly people.

\section{CONCLUSION}

This study exhibited that physical health problem of elderly people was observed the most powerful factor in determining overall QOL index of elderly people followed by psychological state (stress in life)and involvement in social activities respectively. Hence, policy makers and programmed managers need to prioritize investments in healthcare for elderly people in their aim to improve the overall quality of their later life. Besides, working at societal level in order to improve intergenerational bonds for promoting a culture of respect for older people among family members and in society along with improving social and community participation of older people to prevent isolation and improving their QOL.

\section{ACKNOWLEDGEMENTS}

It is researcher's pleasure to thank to the respondents for their cooperation during field study. The researcher is also grateful to Dr Padma Prasad Khatiwada and Dr. HomNathChalise for providing him an important feedback to improve this research paper. Besides that he would like to give his thanks to the Kailali Multiple Campus and staffs for their valuable support.

\section{DECLARATIONS}

\section{Ethical consent to participate}

Respondent's right to refuse and withdraw from the interview at any time was accepted with the maintenance of confidentiality. Respondents were assured of the confidentiality. Thereafter the study sought for the informed verbal consent of respondents before the interview.

\section{Consent to publish}

Not applicable.

\section{Competing interests}

The authors declare that they have no competing interests.

\section{Funding}

Not applicable.

\section{REFERENCES}

1. Singh ML. Aspects of ageing (Ch No. III). Population monograph of Nepal. Kathmandu: Central Bureau of Statistics. 2014; 73-109.

2. https://digitallibrary.un.org/record/130597? ln=en.

3. https://en.wikipedia.org/wiki/Ministry_of_Women,_Children_ and_Senior_Citizens_(Nepal).

4. World Health Organization Quality of Life Group (WHOQOLGroup. WHOQOL User manual. Geneva. 1998.

5. Vijaya P, Akbar S. Handbook of research on geriatric health, treatment, and care. 2018.

6. Campbell A, Converse PE, Rodgers W. The quality of American life: Perceptions, evaluations and satisfactions. New York: Russell Sage Foundation, USA. 1976.

7. Tesch-Roemer C. Active ageing and quality of life in old age. United Nations Economic Commission for Europe (UNECE), New York, USA. 2012.

8. Subedi BP. The aged and the marginal: Social geography of Nepal. The Himalayan Review. 2004; 35(1): 1-18.

9. Chalise HN, Kai I, Saito T. Self-reported health: A study of older adults from a developing country like Nepal. Bio-Sci Trends. 2007; 1(2): $102-107$

10. Chalise HN. Social Support and its Correlation with Loneliness and Subjective Well-being: A cross-cultural study of older Nepalese adults. Asian Social Work and Policy Review. 2010; 4(1): 1-25.

11. Chalise HN, Rai SL. Prevalence and correlates of depression among Nepalese Rai older adults. J Gerontol Geriatr Res. 2013; 2(4): 1-5.

12. Chalise HN, Lamsal U. Walking and sleep quality of Nepalese older adults resid-ing in an old age home. J Gerontol Geriatr Med. 2017; $3: 1-4$. 
13. Chalise HN, Basnet M. Abuse of older adults residing in the community of Nepal. J Gerontol Geriatr Res. 2017; 6(2): 1-5.

14. Joshi MR, Chalise HN, Khatiwada PP. Quality of life of Nepalese elderly living in rural Nepal. J Gerontol Geriatr Res. 2018; 7(5): 1-6.

15. Joshi MR. Living arrangements and quality of life of Nepalese elderly in rural Nepal. Indian J Gerontol. 2019; 32(2): 178-192.

16. Joshi MR. Physical and mental health status of of elderly people in urban setting in Nepal. Indian J Gerontol. 2018; 32(4): 382-393.

17. Yamane T. Statistics: An introductory analysis (2nd Edition) New York: Harper and Row, New York, USA. 1967.

18. Gabriel Z, Bowling A. Quality of life from perspective of older people. Ageing and Society. 2004; 24: 675-691.

19. https://shodhganga.inflibnet.ac.in/bitstream/10603/5653/1/01_ title.pdf

20. https://shodhganga.inflibnet.ac.in/bitstream/10603/19504/1/01_ title.pdf
21. Gupta A, Mohan U, Tiwari SC, Singh SK, Singh VK. Dimensions and determinants of quality of life among senior citizens of Lucknow, India. Int J Med Public Health. 2014; 4(4): 477-481.

22. Avolio M, Montagnoli S, Marino M, Basso D, Fluria G, Ricciardi W, et al. Factors influencing quality of life for disabled and nondisabled elderly population The results of a multiple correspondence analysis. Curr Gerontol Geriat Res. 2013; 13: 1-6.

23. Qin H. Adding life to years: Predicting subjective quality of life among oldest old. Gerontolo Theses, Georgia state university, Georgia, USA. 2007.

24. Hameed S, Brahmbhatt K, Patip DC, Prasanna KS, Jayara S. Quality of life among the geriatric population in a rural area of Dakshina Kannada, Karnataka, India. Global J Med and Public Health. 2014; $3(3): 1-5$.

25. Dongre AR, Deshmukh PR. Social determinants of quality of elderly life in rural setting of India. Indian J Palliat Care. 2012; 18(3): 181-189. 